DOI 10.37882/2500-3682.2020.08.15

\title{
ФОРМИРОВАНИЕ И РАЗВИТИЕ ВОЕННО-ПРОФЕССИОНАЛЬНОЙ НАПРАВЛЕННОСТИ ВОСПИТАННИКОВ КАДЕТСКИХ УЧИЛИЩ МОРФ
}

\section{FORMATION AND DEVELOPMENT \\ OF THE MILITARY-PROFESSIONAL ORIENTATION OF PUPILS OF CADET SCHOOLS OF THE MINISTRY OF DEFENSE OF THE RUSSIAN FEDERATION}

\section{Naydenova}

Summary: The article contains the results of a scientific study on the urgent problem of the formation and development of the military professional orientation of pupils of cadet schools of the Ministry of Defense of the Russian Federation, as potential cadets of military universities, the conditions of its formation and development. The article presents a comparative analysis of the development of the military professional orientation of the cadets, recommendations are developed to increase the military professional orientation of the cadets.

Keywords: cadet education; cadet education; military professional orientation; cadet school; professionally important qualities.

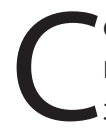
оциально-экономические и политические процессы, происходящие в последнее время в России, затрагивают и его Вооружённые Силы. Подготовка профессиональных военных кадров требует новых подходов к образованию, обучению и воспитанию воспитанников кадетских училищ МО РФ, высоких требований к ним.

На современном этапе руководство Министерства обороны РФ уделяет большое внимание подготовке выпускников довузовских образовательных организаций к формированию и развитию военно-профессиональной направленности, качественно меняя характер требований к выпускникам кадетских училищ МО РФ.

Военно-профессиональная направленность занимает важное место в структуре личности воспитанников кадетских училищ Министерства обороны Российской Федерации и играет огромную роль в формировании и развитии профессионально важных качеств личности кадет. Она включает интерес к военной профессии, призвание, профессиональные намерения и ожидания, склонности и способности на будущем военном поприще. В связи с этим актуальными становятся требования по подготовке кадет как будущих офицеров:
Найденова Ирина Алексеевна

Аспирант, ОАНО ВО «МПСУ»; педагог- психолог, ФГКОу «Оренбургское президентское кадетское училище», naydenova1968@mail.ru

Аннотация: Статья содержит результаты научного исследования по актуальной проблеме формирования и развития военно-профессиональной направленности воспитанников кадетских училищ МО РФ, как потенциальных курсантов военных вузов, условиях ее формирования и развития. В статье представлен сравнительный анализ развития военно-профессиональной направленности кадет, разработаны рекомендации по повышению военнопрофессиональной направленности кадет.

Ключевые слова: кадетское образование; кадетское воспитание; военно-профессиональная направленность; кадетское училище; профессионально-важные качества.

- повышение и устойчивость военно-профессиональной направленности воспитанников;

- внедрение мероприятий и учебных дисциплин в учебно-воспитательном процессе кадетского училища с учетом реализация военной составляющей;

- совершенствования военно-профессионального саморазвития, самопознания и самосовершенствования кадет;

- воспитание у кадет профессионально-важных качеств таких качеств, как способность взять на себя ответственность за решение сложных задач, умение поддержать инициативу, мобилизовать свою волю в трудных жизненных ситуациях. [5, с. 31-33].

Гипотеза исследования: состоит в предложении о том, что развитие военно-профессиональной направленности кадет будет продуктивнее при следующих педагогических условиях:

- рассматривать педагогические условия формирования военно-профессиональной направленности кадет как важнейший фактор данного процесса;

- учебно-воспитательный процесс в условиях кадетского училища строится на основе разрабо- 
танной программы военно-профессиональной ориентации воспитанников, с учетом возрастных особенностей кадет.

Формирование и развитие военно-профессиональной направленности личности изучали такие военные психологи и педагоги В.Н. Ромашин А.Ю. Асриев, В.П. Дьяченко, Л.Ф. Железняк, Л.А. Кандыбович, И.Б. Нагаев, А.В. Барабанщиков, Н.Ф. Феденко и др. Основными положениями об основных понятиях развития психологического процесса занимались (А.В. Барабанщиков, С.Л. Рубинштейн, В.С. Мерлин, А.Н. Леонтьев, П.Н. Городов, Г.И. Щукина, А.В. Петровский и др.). О непрерывном процессе развивающего обучения и воспитания идеи дидактики рассматривали в своих работах (Ю.К. Бабанский, Н.В. Кузмина, В.Н. Герасимов, Ю.И. Тарский и др.). Выводы и положения по проблемам оптимальности и преемственности в профессиональной подготовке кадров изучали и определили (Ю.К. Бабанский, Л.Г. Лаптев, В.П. Жуковский и др.). Основные теории и практики формирования военно-профессиональной направленности были досконально изучены и разобраны (Кандыбович Л., М.И. Феденко, Л.Ф. Железняк, и др.) .Мотивации военно-профессионального самовоспитания и самосовершенствования в воинской деятельности описали (В.В. Богуславский, Г.А. Волковицкий, Л.Н. Уваров, А.А. Кобенко и др.). [8, с.24-26]. В работе под термином «уровень военно-профессиональной направленности» понимается степень сформированности профессионально-важных качеств у кадет, в соответствии с их возрастными возможностями.

В педагогике принят уровневый подход при характеристике сформированности качеств личности. Так, В.И. Лутовинов, Ю.П. Квятковский, Т.Д. Дубовицкая, Л.Ф. Железняк, выделяют три уровня профессиональной направленности: высокий, средний и низкий.

При важности отмеченных исследований степень разработанности проблемы формирования военно-профессиональной направленности кадет является недостаточной: вне поля зрения исследователей остался вопрос о значении военно-профессиональной направленности кадет-выпускников при поступлении в военные вузы и проблема формирования направленности в процессе дальнейшего обучения. Практически отсутствуют исследования, посвященные педагогическим условиям формирования военно-профессиональной направленности воспитанников кадетских училищ МО РФ.

В научно-теоретическом плане актуальность исследования определяется необходимостью преодолеть фрагментарность данных о технологиях развития профессиональной направленности личности, выработать целостные теоретические представления о развитии военно-профессиональной направленности будущих офи- церов в кадетском училище.

Bсе сказанное выше позволило выявить противоречие между потребностью общества в офицерах с развитой военно-профессиональной направленностью и недостаточной разработанностью научно-методических основ её формирования в реальном образовательном процессе довузовской образовательной организации MO PФ.

Указанное противоречие позволило сформулировать проблему исследования - каковы теоретические предпосылки и технология эффективного формирования военно-профессиональной направленности кадет в учебно-воспитательном процессе кадетского училища. Решение данной проблемы составило цель исследования.

Цель данной статьи - выявить уровень развития военно-профессиональной направленности воспитанников в процессе обучения в кадетском училище.

Объект: исследования- военно-профессиональная направленность воспитанников кадетских училищ МО РФ. В соответствии с проблемой, объектом исследования поставлены следующие задачи:

- проанализировать научную литературу с целью раскрытия сущности понятия «военно-профессиональная направленность личности;

- экспериментально исследовать психологические особенности развития военно-профессиональной направленности личности воспитанников кадетского училища;

- разработать рекомендации по повышению уровня военно-профессиональной направленности кадет в разные возрастные периоды обучения в кадетском училище.

Военно-профессиональная ориентация включает в себя:

- формирование у кадет военно-профессиональной направленности, психологической готовности к осознанному выбору профессии офицера с учетом склонностей, способностей и особенностей личностного развития;

- адресное психологическое сопровождение выбора профессии посредством внедрения индивидуальных рекомендаций по саморазвитию и профессиональному самоопределению кадет на этапе ранней предпрофильной и профильной подготовки;

- разъяснение требований военно-профессиональной деятельности к индивидуальным психологическим качествам и оказание помощи в выборе конкретной военной специальности в соответствии с интересами и склонностями кадет; 
- формирование мотивации у кадет к самовоспитанию волевых качеств;

- привлечение к поступлению в вузы МО РФ наиболее подготовленных и дисциплинированных кадет, способных овладеть знаниями и практическими навыками, необходимыми для успешного исполнения служебных обязанностей на должностях офицерского состава.

Для того чтобы определить результативность развития и сформированности военно-профессиональной направленности в кадетском училище использовали социально-педагогический мониторинг. В проведенном исследовании в качестве основного средства мониторинга выступал набор анкет для различных возрастных категорий кадет, который позволил выявить изменения в развитии военно-профессиональной направленности кадет в зависимости от возрастного периода обучения в училище.

Исследования проводились с помощью анкет: «Моя будущая профессия», анкета «Военно-профессиональная направленность кадет» и по трём методикам: «Краткий ориентировочный тест» (KOT), (S-test), «Опросник военно-профессиональной пригодности» (ВПП).

Анализ показателей развития военно-профессиональной направленности воспитанников 5-7 классов на начальном этапе позволил сделать вывод о преобладании среднего уровня сформированности военно-профессиональной направленности у $76 \%$ респондентов, лишь у $24 \%$ респондентов был выявлен низкий уровень развития военно-профессиональной направленности.

85\% респондентов 5 классов выбирают военную профессию. Но вместе с этим, незначительная часть 15\% респондентов ориентированы на гражданскую службу $46 \%$ респондентов отмечают, что на выбор профессии большее влияние оказывают родители; 64\% респондентов считают, что самостоятельно выбрал военную профессии, без какого-либо влияния со стороны, полагаясь на свои интересы и способности.

По результатам анкетирования 6 классов самой популярной оказалась военная сфера. На ней остановили свой выбор 64\%респондентов. Но вместе с этим, 36\% респондентов ориентированы на гражданскую службу.

Основными преимуществами будущей профессии для респондентов являются: «быть защитником Родины» - 56\%; «найти применение моим способностям»-38\%.

Качества характера, необходимые для того, чтобы состояться в выбранной профессии респонденты отметили, такие как самостоятельность, терпение, трудолюбие, мужество, отвага, доброта, образованность, смекалка и сосредоточенность. Следует отметить, что по результатам анкетирования респондентов 5-6 классов роль педагогов в их военно-профессиональной ориентации является ведущей.

Результаты респондентов 7 классов показали, что 85\% уверенны, что образовательная среда кадетского училища способствует выбору военной специальности в будущем. 63\% респондентов уже сейчас уверены, что в будущем будут поступать в военные вузы МО РФ. На первом месте у 59\% опрошенных респондентов стоят понятия о высоких морально-волевых качествах военнослужащего. А это является важным компонентом формирования и укрепления здоровых ценностных ориентаций подростков и результатом эффективного воспитания 85\% респондентов отмечают, что училище дает возможность получить достойное и хорошее образование, 49\% отмечают, что обучение в ОПКУ способствует физическому и духовному развитию молодых людей. 72\% респондентов положительно относится к мероприятиям военно-патриотической направленности и с удовольствием принимает в них участие 78\% респондентов на вопрос о готовности пожертвовать собой ради России ответили утвердительно. Полученные результаты отражают возрастные особенности респондентов, которые, несмотря на выраженное стремление к самостоятельности в принятии решений, во многом зависимы от взрослых и нуждаются в их дальнейшей поддержке. 58\% респондентов 7 классов рассматривают карьеру офицера как приоритетную в выборе профессии после окончания училища.

По результатам исследования можно сделать соответствующие выводы, чем взрослее становятся респонденты, тем больше задумываются над выбором профессии военного, соизмеряя со своими способностями и возможностями. Если в 5 классах 85\% кадет выбирает профессию офицера. Необходимо учитывать, что обучение в училище на данном этапе в первую очередь привлекает их внешней стороной (ношение формы, новый социальный статус, новый распорядок дня и др.). То в 6 классах $64 \%$ респондентов хотят быть военными. В 7 классах 63\% респондентов выбирают профессию офицера.

Полученные данные убеждают в актуальности поставленного вопроса и говорят о безусловной необходимости системного педагогического сопровождения формирования военно-профессиональной направленности Проведенное анкетирование в 8 - 9 классах показало, что у $58 \%$ респондентов обнаружена достаточно зрелая социальная позиция, считающих выбор будущей профессиональной деятельности обусловленностью своей гражданской позицией и сформированностью патриотических чувств привитыми в кадетском училище.

42 \% респондентов нельзя сказать, что они облада- 
ют в полной мере развитыми профессионально-важными качествами. Хотя $85 \%$ респондентов 8 классов считают, что условия училища способствуют развитию профессиональных интересов благодаря проводимым воспитательным мероприятиям, учебному процессу, дополнительному образованию и др.).58\% респондентов рассматривают карьеру офицера как приоритетную в выборе профессии после окончания училища. При анализе ответов кадет на вопрос о личной значимости профессии офицера, отмечается, что большинством респондентами 76\% осознается основная роль офицера как защитника Родины. На втором месте стоит возможность быть максимально полезным для общества составляет $46 \%$. И на третьем месте, что составляет $41 \%$ выступает личная заинтересованность респондентов, как «возможность достичь высокого положения в обществе».

78\% респондентов по окончании 9 класса планируют продолжить обучение в Оренбургском президентском кадетском училище до 11 класса. 83\% респондентов считают, что образовательная среда в училище помогает им в выборе будущей специальности. $60 \%$ респондентов планируют после окончания кадетского училища поступать в вузы МО РФ, 26\% уже сейчас выбирают гражданскую профессию, 14\% пока до конца не определились с этим вопросом.

58\% респондентов 9 классов отметили, что сами определяют свое отношение к выбору профессии, демонстрируя тем самым независимость и самостоятель- ность своей точки зрения, 32\% указали семью, 21\% воспитателей и педагогов училища.

Осознанный выбор профессии респондентами 1011 классов является следствием решения возрастных задач. Формирование внутренней готовности кадет к осознанному и самостоятельному планированию, корректировке своих профессиональных планов и интересов на основе самопознания, возможно только при условии эффективного психолого-педагогического сопровождения. 70 респондентов 10-11 классов выбирают вузы МО РФ,19\% гражданские вузы, $11 \%$ так и не смогли определиться с выбором.

На основании результатов исследования можно отметить, что: 18\% респондентов имеют высокий уровень сформированности военно-профессиональной направленности. Отмечается позитивное отношение к военной службе в целом, выраженный интерес к овладению воинскими специальностями, с ярко выраженной мотивацией достижения успеха, готовностью преодолевать возможные трудности на пути к достижению цели. Их отличает высокий уровень самооценки, разнообразные интересы, высокий уровень активности. Положительное отношение к военной службе, готовность к овладению воинскими специальностями, достаточно высокий уровень активности с выраженной мотивацией отмечается у $69 \%$ респондентов выше среднего, хороший уровень респондентов. Умеренно выраженную положительную направленность на овладение воинскими специальностями показали $13 \%$ респондентов.

Диаграмма №1.

Уровень развития военно-профессиональной направленности кадет 5-11 классов

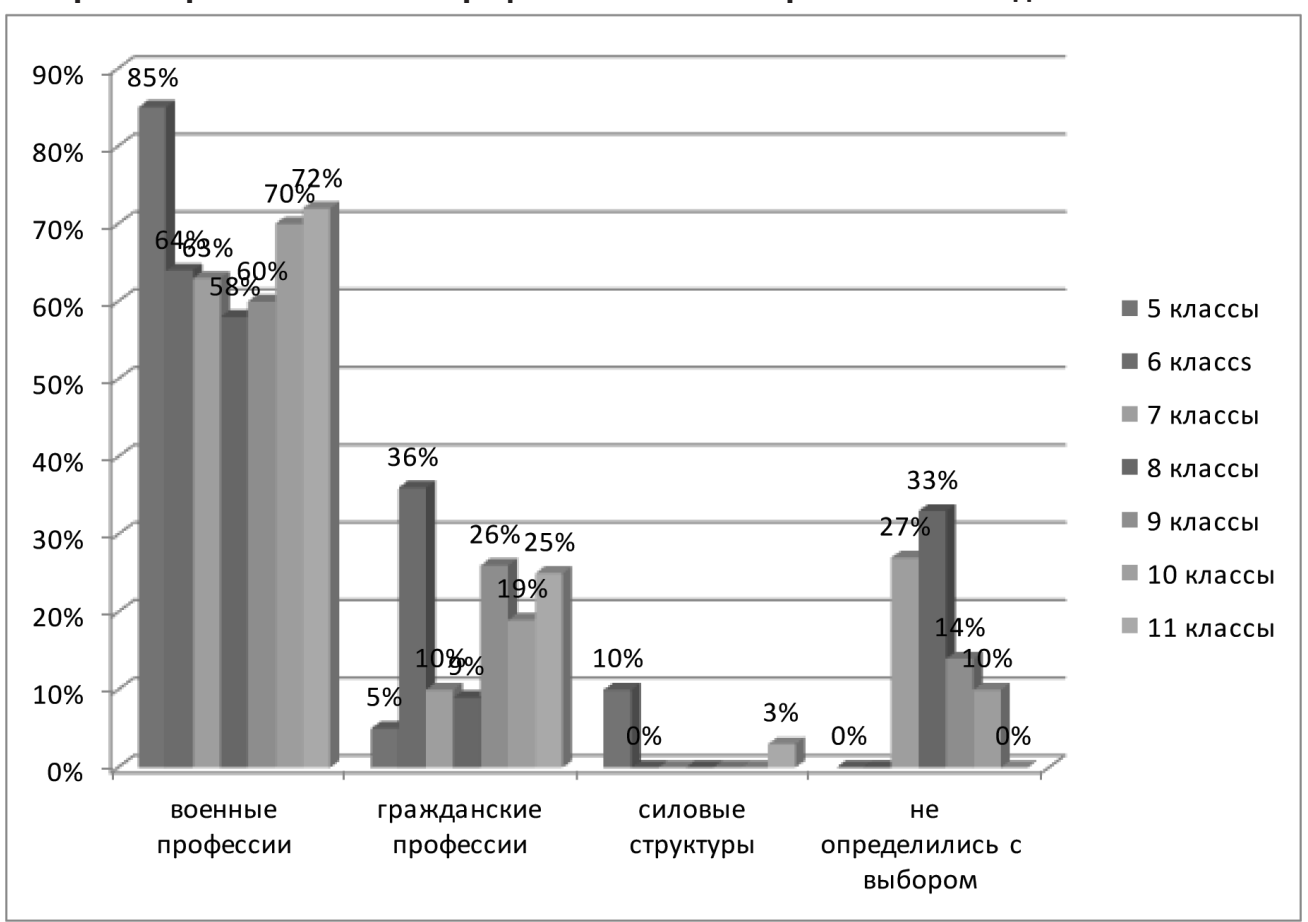


Сравнивая показатели военно-профессиональной направленности воспитанников кадетского училища, можно отметить, что просматривается волнообразная тенденция к повышению уровня данного показателя в процессе обучения в довузовском образовательном заведение. К концу обучения в кадетском училище (выпускной курс) у кадет преобладает высокий уровень и уровень выше среднего сформированности военнопрофессиональной направленности. По результатам исследования разработаны рекомендации по повышению уровня военно-профессиональной направленности кадет период обучения в кадетском училище.

Таким образом, цель достигнута, задачи решены, выдвинутая гипотеза получила полное эмпирическое подтверждение.

Выполненное исследование не исчерпывает всех аспектов проблемы, но существенно дополняет разделы изучения психологических особенностей развития военно-профессиональной направленности воспитанников кадетских училищ, открывает новые перспективы для дальнейших исследований данной проблемы в области психолого-педагогических дисциплин. Сравнивая уровень развития и сформированности показателей военно-профессиональной направленности кадет, можно отметить тенденцию их повышения. К концу обучения (7 курс) у кадет выпускников определяется высокий уровень развития военно-профессиональной мотивации. Компетентные педагоги, воспитатели, офицеры создал здоровую, психологически комфортную атмосферу в училище, сумели привить кадетам интерес к учебной деятельности. Как следствие, кадеты Оренбургского президентского кадетского училища показали высокие результаты развития военно-профессиональной направленности. В училище внимание уделяется военнопатриотическому воспитанию облучающихся, подготовке юношей к выбору военного вуза. В училище созданы все необходимые условия по развитию и формированию военно-профессиональной направленности кадет. Полученные в ходе названного исследования аналитические данные, позволили не только выработать рекомендации по совершенствованию подготовки кадет к выбору военного вуза и предложить конкретные пути по повышению качества обучения в целом в довузовских образовательных учреждениях, определить основные направления по индивидуальной работе с кадетами, испытывающими трудности в психологической адаптации к выбору военной специальности.

\section{Рекомендашии:}

Оценивать возможности поступления в высшее военное учебное заведение с учетом уровня успеваемости, состояния здоровья, физической подготовленности каждого кадета; при необходимости - корректировать выбор профиля учебного заведения и военной специальности.

Осуществлять контроль за ходом формирования военно - профессиональной направленности личности на каждом возрастном этапе /контроль знаний, оценка профессионально значимых свойств и качеств личности каждого кадета/.

Координировать работу классных руководителей по преемственности проф. ориентационной работы между ступенями образования, по организации индивидуальной работы с обучающимися и их родителями для формирования обоснованных профессиональных намерений в выборе профессии офицера.

Педагогическому коллективу проводить активное военно-профессиональное просвещение кадет посредством реализации основных и дополнительных образовательных программ.

\section{ЛИТЕРАТУРА}

1. Асмолов А.Г. Психология личности: принципы общепсихологического анализа. М., 2001.С 234-236.

2. Божович Л.И. Проблемы формирования личности: избранные психологические труды //Под ред. Д.И. Фельдштейна М.: Московский психолого-социальный институт; Воронеж: НПО «МОДОК», 2001.

3. Вагнер И.В. Механизмы развития у школьников опыта самоопределения в ситуациях выбора в условиях реализации программ воспитания и социализации. Часть 3. Социальное проектирование: проектная деятельность как форма реализации детских социальных инициатив /И.В. Вагнер// Вопросы науки. - 2014. - № 1(6).- С.22-29.

4. Жукова Е.Ю. Формирование у кадет ценностного отношения к воинскому долгу. Современные проблемы науки и образования. М., 2012 . - № 3.

5. Лалаев М.С. Кадетские корпуса России //Исторический очерк вузов, подведомственных Главному их Управлению М., 1980.С. 31-33.

6. Педагогический сборник / ред. Н.Х. Весель, А.К Острогодский, И.С. Симонов. - СПб. -Несколько слов о наших кадетских корпусах// Педагогический сборник.- $1903-$ №7.

7. Томилин А.Н. Концепция формирования профессиональной направленности офицера-воспитателя ВМФ. Учеб.-метод. пособие. - Новороссийск: МГА им. адм. Ф. Ф. Ушакова, 2010.

8. Филиппов Э.М. Кадетские корпуса в России: прошлое и современность. - СПб.,1997- С.24-26. 